Bentham open
CrossMark
Content list available at: www.benthamopen.com/TOCIEJ/
DOI: $10.2174 / 1874149501711010955$

RESEARCH ARTICLE

\title{
Experimental Study on Flexural Behavior of Precast Concrete Shear Walls with Vertical Joint
}

\author{
Guangming Qiu ${ }^{1}$, Jiliang Liu ${ }^{1}$, Mingjin $\mathrm{Chu}^{2, *}$, Gang Wang ${ }^{1}$ and Muhe Liu ${ }^{1}$ \\ ${ }^{I}$ School of Civil Engineering, Yantai University, 264005, Yantai, China \\ ${ }^{2}$ Beijing Advanced Innovation Center for Future Urban Design, Beijing University of Civil Engineering and \\ Architecture, 100044, Beijing, China
}

Received: January 03, 2017

Revised: March 15, 2017

Accepted: May 05, 2017

\begin{abstract}
:
Background:

To study the flexural behaviors of the concrete shear walls with precast hollow slab, one cast in-situ reinforced concrete shear wall and two precast two-way hollow slab shear walls (PTHSWs) vertical joint were tested under low cyclic loading.
\end{abstract}

\section{Objective:}

The study showed that vertical joints of PTHSW are safe and reliable to ensure the effective connection between the assembly units. The ductility coefficient of shear wall is larger than 7, so this kind of shear wall has good ability of deformation especially under earthquake load.

Results:

The interface can effectively ensure the integral performance of PTHSWs and its effect on the flexural behaviors of PTHSWs could be ignored.

Keywords: Precast concrete shear wall, Hollow slabs, Flexural behavior, Ductility, Vertical joint, PTHSW.

\section{INTRODUCTION}

Precast concrete shear wall structure is a monolithic structure which is assembled and connected in the construction site. Its' basic assembly unit is a precast or a semi-precast concrete panel. The new-typed structure has many advantages, such as easy construction, rapid construction speed and good energy conservation thus it becomes an important form in the industrialized building area $[1,2]$. The connection technology is the key to the new-typed structure. The performance of connection determines the integrity of the structure.

Liuhe Cai [3] tested three assembled shear walls with shaped steel under low cyclic loading. The results show that the connection method with shaped steel has a good seismic capacity. NIST research project [4] researched vertical joints connected with bolts and welds under low cyclic loading, the results show that both the sliding friction energy dissipation bolt connection and the u-shaped plate bending energy dissipation bolt connection have a good performance, even the sliding friction bolt connection have a better performance in energy dissipation. Guohua song $[5,6]$ tested vertical joints of eighteen specimens under low cyclic loading, the results indicate that: the maximum shear capacity of vertical joints increases with the increasing of diameter combination and has a nonlinear relationship with the width of vertical joints. PTHSW structure is a new-typed precast concrete shear wall structure. Its basic assembly unit is a precast two-way hollow slab with vertical and horizontal holes inside. The precast two-way hollow slab is shown in

\footnotetext{
* Address correspondence to this author at the School of Civil Engineering, Yantai University, Yantai, 264005, China; Tel: +86 535 6902606; Fax:
} +86 535 6902606; E-mail: housind@126.com 
Fig. (1). The reinforcement is placed into the horizontal and vertical hollow holes. And then concrete is poured into the holes to form an integral structure. The vertical joint of PTHSWs is mainly composed of interfaces between cast in-situ and precast concrete, cast in-situ concrete located in the hollow holes of the precast two-way hollow slab and the horizontal reinforcement. Mingjin Chu [7, 8] studied the shear performance of PTHSWs with vertical joint. It can be concluded that the connection of vertical joint is reasonable and reliable which can be used for practical engineering. However, the flexural performance of PTHSWs with vertical joint has not been reported now. To study the flexural behaviors of PTHSWs and the mechanical performance of vertical joint, a reinforced concrete shear wall and two PTHSWs were designed according to the principle of "strong shear weak bending". The research results will provide certain theoretical basis for the engineering application of the PTHSW structure.

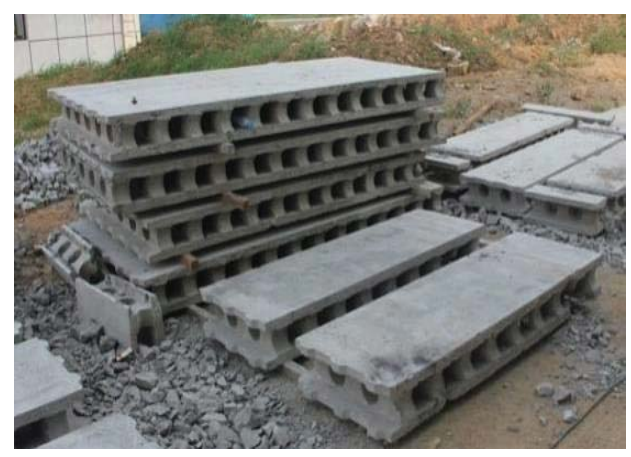

Fig. (1). Precast hollow slabs.

\section{GENERAL SITUATION OF EXPERIMENT}

\subsection{Design and Production of Specimens}

Three specimens are designed in this article. They are the reinforced concrete shear wall specimen BW01, the PTHSW specimen without vertical joint BSW1 and the PTHSW specimen with vertical joint BDW1. The height of specimens is $3200 \mathrm{~mm}$ with the same shear span ratio as 2.0 and the dimension of the cross section size is $1600 \mathrm{~mm} \times 200 \mathrm{~mm}$. BW01 and BSW1 are both composed of the middle and the boundary elements, while the length of the later is $210 \mathrm{~mm}$. BDW1 is composed of the wall in the middle, the boundary elements and the vertical joint with $20 \mathrm{~mm}$ width, while the length of the boundary elements is $200 \mathrm{~mm}$. The axial compression ratio of all specimens is 0.15 .
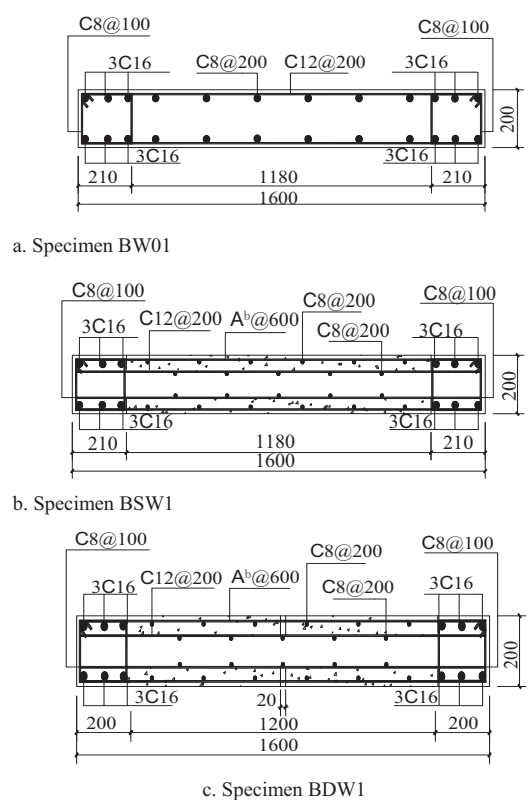

Fig. (2). Dimensions and reinforcement details of specimens. 
The reinforcement details of specimens are showed in Fig. (2). All specimens are designed according to the principle of strong shear weak bending. The longitudinal reinforcement in the boundary element was high-tensile deformed steel bars of $16 \mathrm{~mm}$ diameter respectively; the stirrups of it were high-tensile deformed steel bars of $8 \mathrm{~mm}$ diameter, and the space was $100 \mathrm{~mm}$; the horizontal distribution reinforcement and the vertical distribution reinforcement were double high-tensile deformed steel bars of $12 \mathrm{~mm}$ and $8 \mathrm{~mm}$ diameter, respectively, and the space was $200 \mathrm{~mm}$. The horizontal distribution reinforcement of BSW1 and BDW1 was placed in horizontal hollow holes; meanwhile the vertical distribution reinforcement was placed in the hollow slabs.

Dimensions and reinforcement details of the precast hollow slabs are shown in Fig. (3). The dimension of the precast hollow slab is $2700 \mathrm{~mm} \times 1180 \mathrm{~mm} \times 200 \mathrm{~mm}$. The vertical hole is circular, and the diameter and the space of it are $104 \mathrm{~mm}$ and $200 \mathrm{~mm}$, respectively. The horizontal hole is square, and the side and the space of it is $120 \mathrm{~mm}$ and $200 \mathrm{~mm}$, respectively. The horizontal distribution reinforcement was placed in the horizontal holes with its ends embedded into the boundary elements for $180 \mathrm{~mm}$. It can provide enough anti-shear capacity of walls and can also effectively connect the wall body and the boundary elements. Because of the height of the PTHSWs is greater than the precast hollow slab, $500 \mathrm{~mm}$ height cast in-situ concrete was poured between the hollow slab and the load beam. Meanwhile, two hightensile deformed steel bars of $8 \mathrm{~mm}$ diameter were placed in each vertical hollow hole at the bottom of the precast hollow slab to connect the foundation beam and the wall body, with the length embedded in the foundation beam of them is $410 \mathrm{~mm}$.

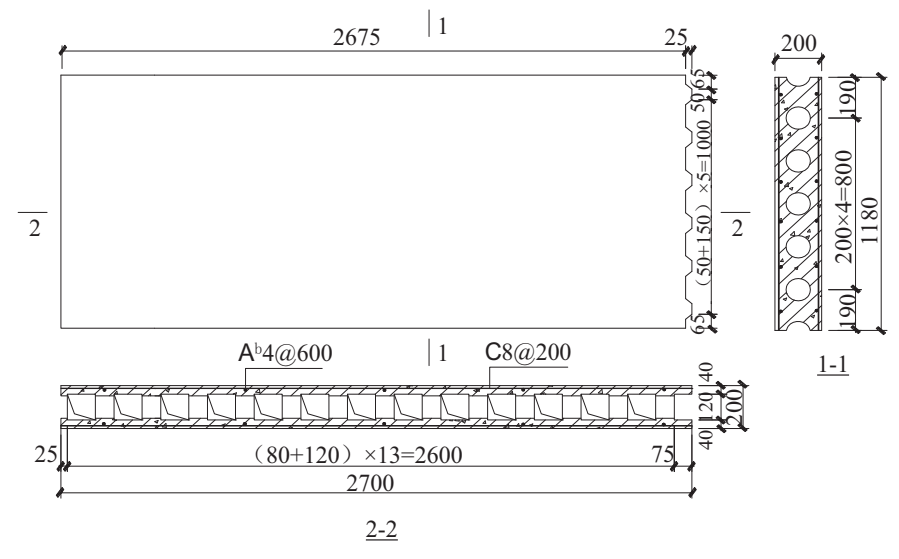

Fig. (3). Dimensions and reinforcement details of the precast two-way hollow slabs.

\subsection{Material Characteristic}

The dimension of standard concrete test cubes is $150 \mathrm{~mm} \times 150 \mathrm{~mm} \times 150 \mathrm{~mm}$. The standard cubes were reserved while making the shear wall specimens and cured under the same condition with the specimens. The measured cubic compressive strength of concrete was tested at the day of test, which is summarized in Table 1 [9].

The average of the yield strength $\left(f_{\mathbf{y}}\right)$, the ultimate strength $\left(\boldsymbol{f}_{\mathrm{u}}\right)$ and the elongation of reinforcement are shown in Table 2 [10].

Table 1. Measured cubic concrete compressive strength of specimens.

\begin{tabular}{|c|c|c|}
\hline \multirow{2}{*}{ Specimens } & \multicolumn{2}{|c|}{ Measured cubic compression strength of concrete/MPa } \\
\cline { 2 - 3 } & Precast & Post-cast \\
\hline BW01 & - & 43.56 \\
\hline BSW1 & 42.16 & 47.26 \\
\hline BDW1 & 49.72 & 58.22 \\
\hline
\end{tabular}

Table 2. Measured strength of reinforcement.

\begin{tabular}{|c|c|c|c|c|}
\hline Diameter & Position & $f_{\mathrm{y}} / \mathrm{MPa}$ & $f_{\mathrm{u}} / \mathrm{MPa}$ & Elongation/\% \\
\hline 8 & Vertical dowel reinforcement & 370 & 567 & 27.50 \\
\hline 8 & Stirrup in the boundary element & 381 & 569 & 24.17 \\
\hline
\end{tabular}


(Table $\square$ ) contd.....

\begin{tabular}{|c|c|c|c|c|}
\hline Diameter & Position & $f_{\mathrm{y}} / \mathrm{MPa}$ & $f_{\mathrm{u}} / \mathrm{MPa}$ & Elongation/\% \\
\hline 12 & Horizontal distribution reinforcement & 440 & 583 & 25.83 \\
\hline 16 & Longitudinal reinforcement in the boundary element & 514 & 644 & 22.08 \\
\hline
\end{tabular}

Note: The reinforcement in the specimens were all high-tensile deformed steel bars.

\subsection{Method of Test and Measurement}

The axial load is applied by a vertical hydraulic jack and kept constant during the test. The horizontal load is applied by a horizontal hydraulic jack and controlled by the loading displacement control system. In the test, the push horizontal load is considered as positive while the pull is negative. Loading control is adopted at the early stage of the test. The load level differential is $200 \mathrm{kN}$ and each load level needs to be repeated once. Displacement control is adopted after the longitudinal reinforcement in the boundary elements yield. The load level differential is twice the corresponding displacement of this level load. The load difference can be appropriately increased after the specimen comes to the peak load, and each load level needs to be repeated twice [11]. The test can be seen finished when the vertical bearing capacity can not be maintained.

The force transducers are adopted to measure the horizontal load and the axial load. The displacement meters are placed to measure the top horizontal displacement (point MH0 and MH0 standby), translation(BH1) and rotation(EBV1 and WBV1), vertical deformations at different heights on both sides of the wall(EV1 EV5 and WV1 WV5) and sliding deformation of the foundation beam(MHB1 MHB2). The layout of displacement meters is shown in Fig. (4a). Strain gauges are placed to measure the strains of the longitudinal reinforcement in boundary elements, the horizontal distribution reinforcement and the vertical dowel bars, the layout of them are shown in Fig. (4b). All data are real-time monitored and gathered by DH3816N static collection system.

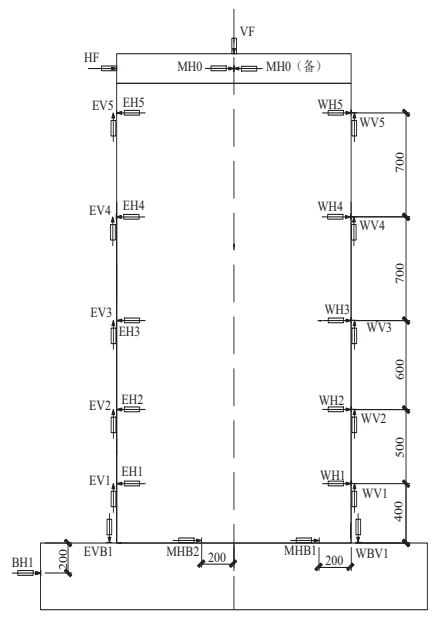

a. Layout of displacement meters

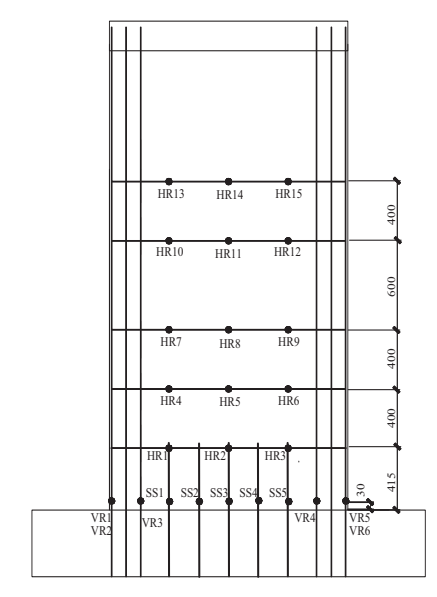

b. Layout of Strain gauges

Fig. (4). Layout of measurement points of PTHSWs. 


\section{PHENOMENON OF TEST}

Failure process and crack distribution of PTHSWs are similar to the reinforced concrete shear wall. Firstly, fine horizontal cracks appeared at the toes of the wall, and then horizontal cracks appeared on the boundary elements. Gradually with the increase of the horizontal load, horizontal cracks developed and extended into the middle of the wall. After that, horizontal cracks turned into diagonal cracks and developed with the degree of $45^{\circ}$. After the longitudinal reinforcement yield in the boundary members, the load method changed into the displacement control; with the increase of the control displacement, the quantity of horizontal cracks and diagonal cracks increased gradually, concrete at toes of the wall was crushed and the horizontal load reached the peak. The crack pattern of specimens at the peak load is shown in Fig. (5). As the control displacement increased, the concrete crushing area at toes of the wall expanded. So, buckling deformation of the longitudinal reinforcement of the boundary elements was serious. Then the horizontal bearing capacity dropped and the vertical bearing capacity was difficult to maintain, and then the test was completed. Concrete of all the boundary elements were seriously crushed and the longitudinal reinforcement of the boundary elements was seriously buckled. The final failure pattern of PTHSWs is bending failure, which is similar to the reinforced concrete shear wall.

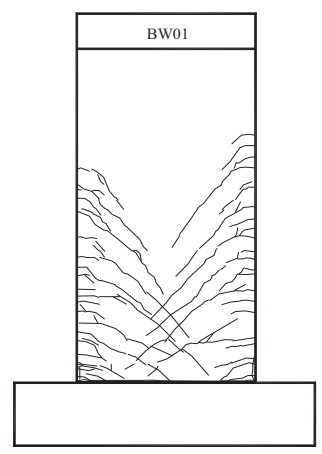

a. Specimen BW01

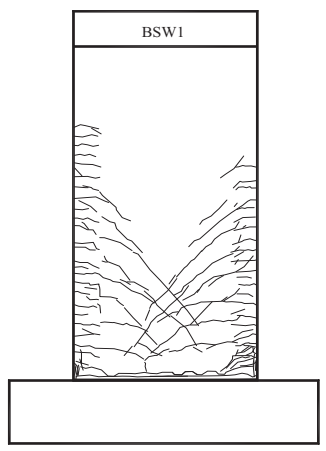

b. Specimen BSW1

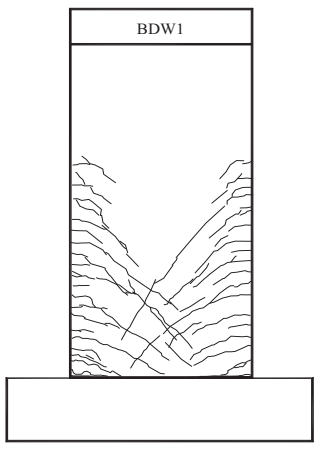

c. Specimen BDW1

Fig. (5). Crushing phenomena of specimens. 
Compared with the reinforced concrete shear wall, the interface between cast in-situ and precast concrete was the weak link of the PTHSWs. At the early stage of the test, the horizontal load was small and the interface was intact, so that the wall was in a state of elastic. With the increase of the horizontal load, concrete at toes of the wall was crushed, the area of it developed and extended toward to the middle of the wall gradually. Then the interface was localized damaged, so, the hollow slab and the post-cast concrete separated. The concrete crushing area expanded which was slightly bigger than the reinforced concrete shear wall. The crushing phenomena of specimens are shown in Fig. (6).

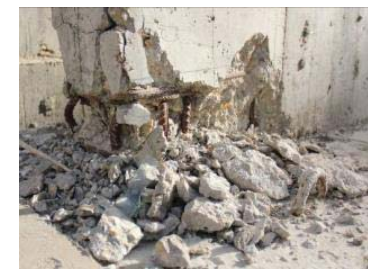

a. Specimen BW01

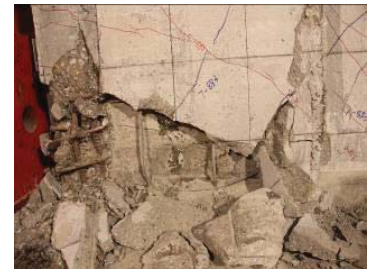

b. Specimen BSW1

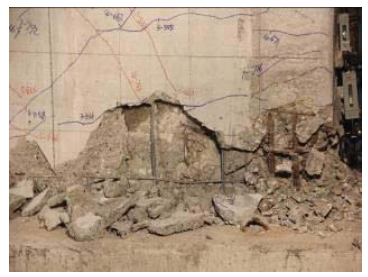

c. Specimen BDW1

Fig. (6). Crushing phenomena of specimens.

Compared with BSW1, the width of vertical joint is increased for BDW1, so the connection of vertical joints is contact without the phenomenon of cracking in the test. It shows that the vertical joint, which is consist of the interface between cast in-situ and precast concrete,the vertical reinforcement and the post-cast concrete, has a good performance in connection.

\section{ANALYSIS OF TEST RESULTS}

\subsection{Curves and Skeleton Curves}

Top horizontal load-displacement hysteretic curves and skeleton curves are respectively shown in Figs. (7 and 8) some conclusions are obtained as follows.

\subsection{Analysis of Bearing Capacity and Ductility}

The characteristic load, characteristic displacements and calculative ductility coefficients are shown in Table $\mathbf{3}$. The yield point was determined by the geometric mapping method [12]. The ultimate point is the state point when the horizontal load is reduced to $85 \%$ of the peak load. From Table 3 , it can be found that:

Table 3. Characteristic points and ductility coefficients.

\begin{tabular}{|c|c|c|c|c|c|c|c|c|c|}
\hline \multirow{2}{*}{ Specimen } & \multirow{2}{*}{ Direction } & \multicolumn{2}{|c|}{ Yield point } & \multicolumn{3}{|c|}{ Peak point } & \multicolumn{2}{|c|}{ Limit point } & \multirow{2}{*}{$\Delta_{\mathrm{u}} / \boldsymbol{\Delta}_{\mathrm{y}}$} \\
\hline & & $P_{\mathrm{y}} / \mathrm{kN}$ & $\Delta_{\mathrm{y}} / \mathbf{m m}$ & $P_{\mathrm{m}} / \mathrm{kN}$ & Average /kN & $\Delta_{\mathrm{m}} / \mathrm{mm}$ & $P_{\mathrm{u}} / \mathrm{kN}$ & $\Delta_{\mathrm{u}} / \mathrm{mm}$ & \\
\hline \multirow{2}{*}{ BW01 } & Push & 609 & 8.32 & 791 & \multirow{2}{*}{831} & 28.54 & 672 & 69.03 & \multirow{2}{*}{ 10. 24} \\
\hline & Pull & 569 & 4.55 & 870 & & 41.08 & 854 & 62.82 & \\
\hline \multirow{2}{*}{ BSW1 } & Push & 589 & 7.10 & 786 & \multirow{2}{*}{839} & 45.45 & 770 & 59.90 & \multirow{2}{*}{ 7. 79} \\
\hline & Pull & 653 & 7.12 & 891 & & 44.99 & 892 & 50.90 & \\
\hline \multirow{2}{*}{ BDW1 } & Push & 646 & 11.83 & 922 & \multirow{2}{*}{960} & 72.62 & 823 & 87.53 & \multirow{2}{*}{ 7. 68} \\
\hline & Pull & 609 & 9.28 & 997 & & 60.91 & 884 & 74.63 & \\
\hline
\end{tabular}

1. The peak load of BSW1 is almost the same as BW01.

2. The bearing capacity of BDW1 is higher than BSW1 due to a higher strength of concrete of BDW1. Meanwhile, 
it further indicates that the vertical joint can ensure the effective connection in horizontal direction of PTHSWs.

3. Ductility coefficients of all specimens are greater than 7. It shows that all specimens have a good ductility.

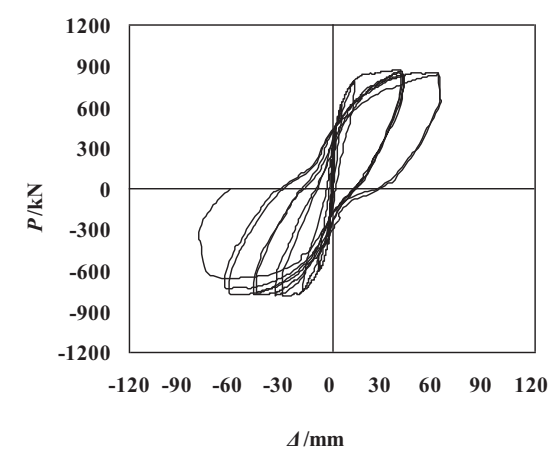

a. Specimen BW01

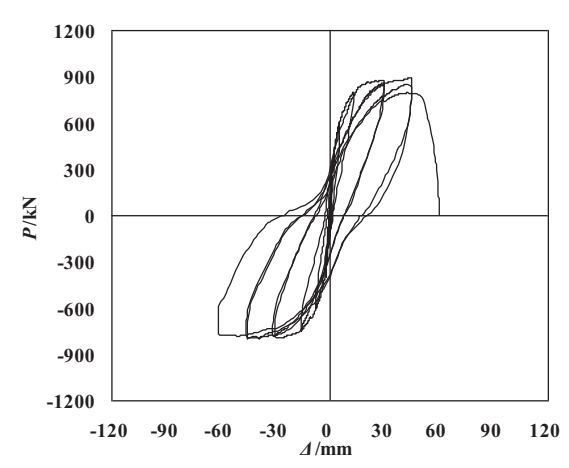

b. Specimen BSW1

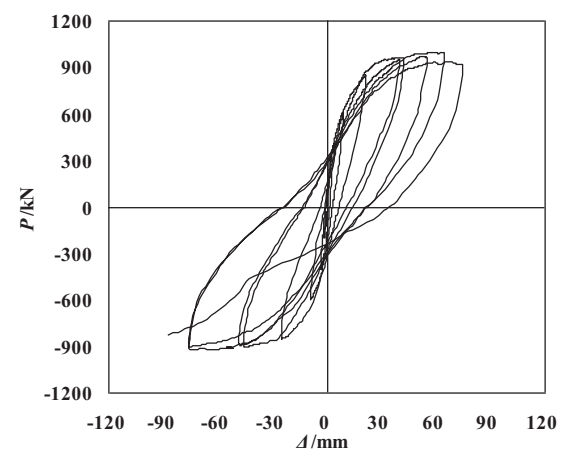

c. Specimen BDW1

Fig. (7). Top lateral load-displacement hysteretic curves.

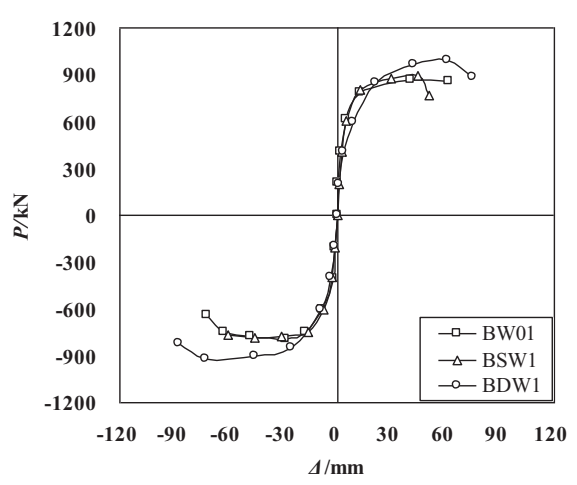

Fig. (8). Top lateral load-displacement skeleton curves. 
1. At the Initial of the test, specimens were in elastic stage and had no cracks. Hysteretic curves presented linear.

2. With the development of the cracks, the residual deformation of the walls increased gradually. Hysteretic curves showed a slight "pinching" phenomenon.

3. The skeleton curve of BW01 was almost coinciding with the skeleton curve of BSW1. It showed that the interface between cast in-situ and precast concrete had a little influence on failure process of PTHSWs.

\subsection{The Composition Analysis of Horizontal Deformation}

Horizontal deformation of a shear wall including three parts: slipping deformation of the bottom of the wall $\left(\Delta_{\mathrm{sl}}\right)$, bending deformation $\left(\Delta_{\mathrm{f}}\right)$ and shear deformation $\left(\Delta_{\mathrm{s}}\right)$. Vertical deformations are measured by placing displacement meter on both sides of the wall, which can be seen in Fig. (4a). Therefore, the cross section rotating angle and the bending deformation can be confirmed, and then got the shear deformation. The measurement result is shown in Fig. (9), it shows that: the slipping deformation of shear walls is very small and less than $4 \%$ of the top horizontal displacement. So, the influence of slipping deformation can be ignored.

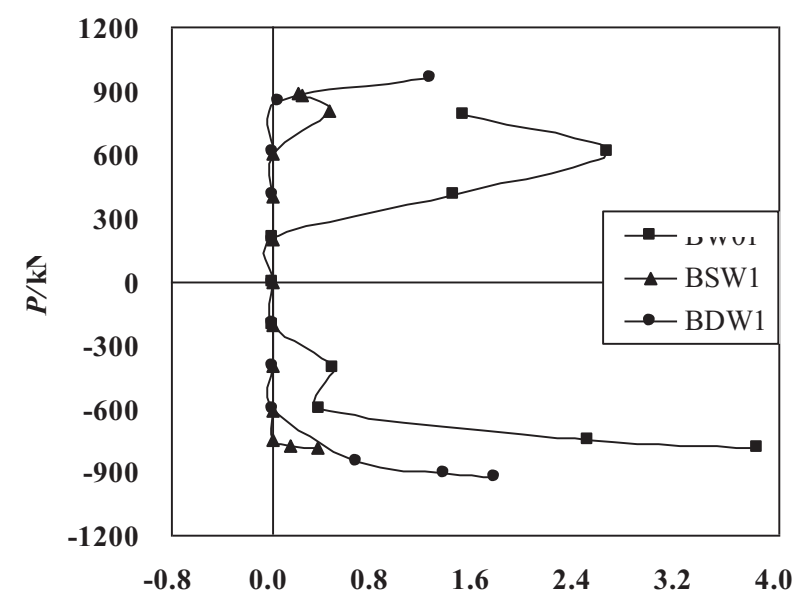

Fig. (9). Horizontal force-slipping deformation skeleton curves.

Fig. (10) shows the proportion of the bending deformation to the total deformation is at the longitudinal axis, while the top horizontal displacement angle at the horizontal axis. In the test, the bending deformation is all the time the main ingredients. Initially, the bending deformation accounted for $60 \%$ of the total displacement. With the increase of the top displacement, diagonal cracks developed fully, then the proportion of bending deformation to total deformation slowly increased until more than $80 \%$.

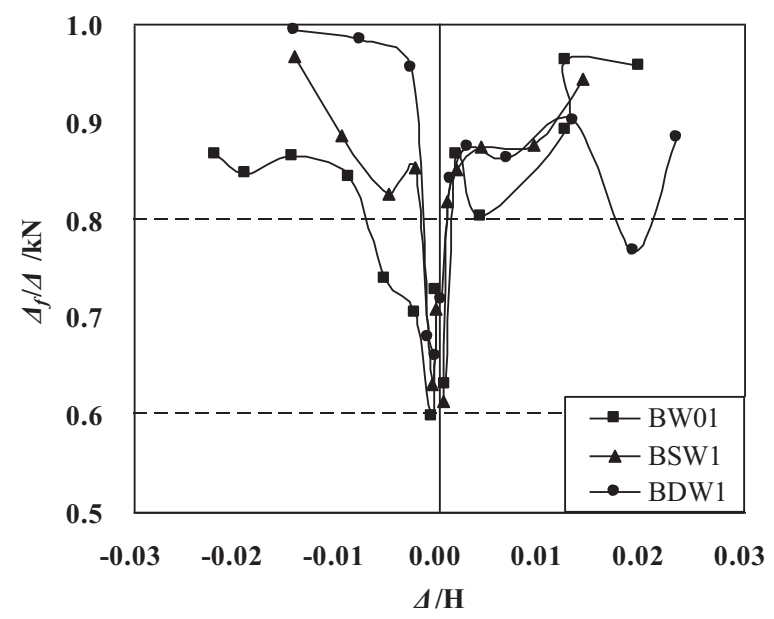

Fig. (10). Deformation component proportion-displacement angle relationship. 


\section{CONCLUSION}

PTHSW structure is a new type of precast concrete shear wall structure. The basic assembly unit is the precast twoway hollow slab. By placing reinforcement in hollow holes and pouring concrete inside, a monolithic structure was assembled and connected. One reinforced concrete shear wall and two PTHSWs were tested, and the failure process and the failure mode of PTHSWs were revealed in this article. The main conclusions are as followed.

1. The development and extension of cracks, the failure process and failure mode of PTHSWs are similar to the reinforced concrete shear wall. The concrete of all the boundary elements was crushed and the longitudinal reinforcement of the boundary elements was buckled when the PTHSWs failed.

2. The ductility coefficients of PTHSWs are larger than 7. The PTHSWs have a good ductility.

3. The vertical joint of PTHSWs can ensure the effective connection of the assembly units, to make the wall safe and reliable.

4. The interface can effectively ensure the integral performance of PTHSWs and its influence on the flexural behaviors of PTHSWs could be ignored.

\section{CONSENT FOR PUBLICATION}

Not applicable.

\section{CONFLICT OF INTEREST}

The authors confirm that this article content has no conflict of interest.

\section{ACKNOWLEDGEMENTS}

The authors are grateful to the support of National Natural Science Foundation of China (Grant No. 51378450, 51508490) and the Project of Shandong Province Higher Educational Science and Technology Program (Grant No. J13LG09).

\section{REFERENCES}

[1] J. Qian, Y. Peng, and J. Zhang, "Test on seismic behavior of pre-cast shear walls with vertical reinforcements spliced by grout sleeve", Engineering Mechanics, vol. 9, no. 2, pp. 1-6, 2011.

[2] W. Xue, J. Yang, and N. Dong, "Experimental study on precast concrete sandwich insulation shear walls under low reversed cyclic loading", Journal of southeast university (Natural science edition), vol. 43, no. 5, pp. 1104-1110, 2013.

[3] L. Cai, W. Li, and Q. Miao, "Seismic test and analysis of horizontal joint of new precast concrete shear walls", In: The 13th high-rise building seismic technology exchange meeting proceedings, 2011, pp. 211-218.

[4] J. Nigel, "The PRESSS program current status and programs the plans for phaseIII", PCI Journal, vol. 9, no. 2, pp. 22-40, 1996.

[5] G. Song, B. Liu, and D. Wang, "Experimental and theoretical study on seismic behavior of vertical connection in PBPS under repeated loading", Journal of building structures, vol. 24, no. 6, pp. 18-24, 2003.

[6] G. Song, D. Wang, and H. Teng, "PRC under repeated load vertical seam strength and stiffness degradation", Earthquake engineering in the world, vol. 21, no. 1, pp. 87-90, 2005.

[7] M. Chu, J. Liu, and H. Cui, "Experimental study on seismic behaviors of assembled monolithic concrete shear walls built with precast twoway hollow slabs with various details", Journal of Building Structures., vol. 35, no. 1, pp. 93-102, 2014.

[8] M. Chu, J. Liu, and H. Cui, "Experimental study on shear behaviors of assembled monolithic concrete shear walls built with precast two-way hollow slabs", Engineering Mechanics, vol. 30, no. 7, pp. 219-229, 2013.

[9] B.S.Y. Ming. Standard for test method of mechanical properties on ordinary concrete GB/T 50081-2002. China Building Industry: Beijing Press, 2003.

[10] "National Standard of the people's Republic of China", Metallic materials-Tensile testing-Part 1: Method of test at room temperature GB/T 228.1-2010., China Building Industry Press: Beijing, 2010

[11] JGJ 101-96 Code for seismic testing of building. Specificating of testing methods for earthquake resistant building, 1997. 
[12] Z. Guo, Theory of reinforced concrete., University of Tsinghua Press: Beijing, 2013.

(c) Qiu et al.; Licensee Bentham Open

This is an open access article licensed under the terms of the Creative Commons Attribution 4.0 International Public License (CC-BY 4.0) (https://creativecommons.org/licenses/by/4.0/legalcode), which permits unrestricted, non-commercial use, distribution and reproduction in any medium, provided the work is properly cited. 